\title{
THE INFLUENCE OF THE MEDIA ON THE MENTAL STATE OF YOUNG PEOPLE
}

\author{
Ganna Sobko 1 \\ ${ }^{I}$ Ph.D., Associate Professor, Professor of Criminal Law, Criminology and Penalty law Department, Odessa \\ State University of Internal Affairs, Odessa, Ukraine, e-mail: sobkoganna1984@ukr.net, ORCID: \\ https://orcid.org/0000-0002-5938-3400
}

Abstract. The article analyzes the concept and content of the media, and how the media affect the mental state of young people. Identified scientists dealing with this issue. It is defined how the media influences the further behavior of young people, namely the choice of idols, style of clothing, profession. What factors are used to influence, namely: TV stars, songs in another language. The media exert social, cultural and psychological influence on society, shaping the needs of people and these needs are not always related to material goods. It is analyzed how the media influences the criminal behavior of young people and with the help of which factors.

Keywords: mass media, mental influence, crime, criminality.

JEL Classification: I30, K24, K33

Formulas: 0; fig.: 1; tabl.: 0; bibl.: 5

Introduction. As a social institution, the media actively use their potential to influence the formation of young people's lifestyles and ways of their integrative behavior. The media have taken their place in the daily life of modern man, firmly settled in it. If we talk about young people, today it is difficult to find a person who can refuse the presence of television and especially the Internet in everyday life. Watching news, advertisements, entertainment programs and shows, TV series, as well as horoscopes, weather forecasts, etc. have firmly entered our lives, and a person is not even aware of the impact that this process has on the formation of his life attitudes, behavioral stereotypes, habits, and everything that makes up our daily lives. And this formation is directly related to the work of the media.

Literature review. In the modern scientific environment, much attention is paid to the study of the media, both domestic and foreign researchers, among which a significant contribution to the study of this issue was made by L. Brown, $\mathrm{Z}$. Brzezinski, H. French, A. Hajiyeva, V. Zdorovega, A. Dolgova, O. Dzoban, V. Pylypchuk, K. Markelova and others.

The issue of human information security has been studied by the following scientists: G. Grechnev, S. Roshchin, V. Sosyna, D. Popov. One cannot disagree with L.M. Rybakova, who claims that without state support the spiritual basis of society is formed by the media, which are subject to the founders, who use information broadcasting methods to broadcast their own limited (social status, worldview, personal experience, responsibility to sponsors, etc.) values. As a result, she writes, we have a crowd of "stars" and "style icons" who demonstrate the personal level of consumption (cars, clothes, accessories, other people's services). It seems that the spiritual "staples" of society are formed and dictated by the glamorous community: overseas villa, foreign educational institutions, foreign shopping, songs in a nonnative language, Hollywood "style icons" and cult works, distant sex symbols, etc [1; 234]. Of course, we can not talk only about the negative impact of the media on lifestyle, habits and values of young people because that would be a one-sided 
approach to the existing problem. The media exert a social, cultural, psychological influence on society, shaping the needs of people, and these needs are not always related to ownership of material goods (although we do not rule this out). These may be needs aimed at human self-development, self-education (for example, a large number of educational lectures on the Internet), raising the cultural level ("Culture" channel), forming attitudes to a healthy lifestyle, motivation to achieve goals. In addition, as the main source of information, and today also the main means of communication, the media traditionally perform important social functions, including communication, education, broadcasting and socializing.

Aims. But the question arises whether these needs are satisfy by the media, and whether their impact is so great directly on the young person's personality and its important life institutions? After all, even in the era of censorship on radio and television, negative trends in the lifestyle of young people were present so not everything was so cloudless.

Methods. The author used the methods of static and logical comparison, systematization and generalization, which made it possible to achieve the goal of the study.

Results. Noting the positive impact of the media and especially the Internet on young people, it is necessary to first analyze the negative impact they have on the majority of the younger generation. Moreover, the results of numerous surveys confirm that under the influence of the media, children and adolescents develop aggression. And the greatest aggression is formed by computer games and modern films. According to a survey conducted by scientists, the majority of respondents (41\%) believe that the media form in Ukrainian children and adolescents mainly negative feelings and attitudes towards people of other nationalities, which is a serious problem for the polyethnic society of Ukraine and can become one of causes of conflicts in the youth environment [2;167 - 168].

The resources of the mass media have enormous opportunities for manipulating human consciousness in the generation of young people and influencing the ways of shaping their way of life. Pitirim Sorokin also listed "aspects of human behavior" that "exhaust the whole way of life of the individual" [3]. And today sociologists, using the term "way of life", mean a set of forms of behavior of the individual, his activity in the sphere of production, everyday life, areas of social, political, cultural and scientific and scientific spheres, as well as meeting social and individual needs. All these forms of behavior are formed under the influence, on the one hand, socioeconomic and political conditions, and on the other hand, mentality, traditions, customs, identity play a significant role. Based on a large number of factors influencing the formation of lifestyle, this definition can be understood as both conscious and spontaneous construction of life on the basis of values, worldviews, mentality, etc. as well as under the influence of external factors, which in the era of information civilization are the media. Today they have a decisive influence on the stereotypes of behavior, strategies and attitudes of the younger generation.

The uncontrolled Internet contains threats to users, especially children and young people, related to the spread of aggressive content $[4 ; 86]$. We can not ignore 
the negative role of increased influence on the youth of social networks, the story of Varvara Karaulova and others clearly show the negative consequences of "living online" [5]. This should be the subject of careful study to prevent or minimize adverse effects. The results of research show that the formation of the image and lifestyle of young people is influenced by the media, which, unfortunately, often have a negative impact on the consciousness and behavior of young people. This is manifested in the fact that the media today do not form stable systematic ideas of young people about the values of life. The picture of the world formed by them is fragmentary and is mediated by the political and economic forces behind them with little state involvement.

It can be concluded that the way of life of young people is formed under the influence of modern media, the analysis of which shows the fragmentary and unsystematic of their policy of forming values, or rather its absence. Characteristic of the present time is the lack of use of modern information channels by public authorities to form youth loyalty to Ukrainian values, education and strengthening of universal values, development of active citizenship, which forms in young people a positive lifestyle. Teenagers deserve special attention as one of the most vulnerable categories of the population. Adolescents watch TV less than primary school children because they spend more time away from home, preferring to communicate with friends. For many teenagers this change of priorities in the sources of information and symbolizes the transition from childhood to adolescence. Teenagers watch TV mostly with their family and to a lesser extent with friends. Listening to popular music becomes a factor that determines the interests and direction of behavior at a given age. Its implementation involves solving adolescent problems such as separation from parents, gaining independence and establishing interpersonal relationships.

The range of programs of interest is expanding. Teenagers still love comedies, but watch less cartoons. In addition to adult-oriented cartoons, they prefer dramas where the main characters are the same teenagers. Girls prefer melodramas, many teenagers watch sports, music and science fiction programs. Adventure and crime themes are less popular. However, very often teenagers watch TV passively, in order to relax when they are tired of communicating with others, or when they are alone.

Adolescence is a period during which children acquire the ability to operate with abstractions, bring the concrete to the general, resolve contradictions of experience and determine the most important in many situations. Teenagers are no longer so strongly connected to the immediate present and can predict the possible future. They realize that the relationship on the screen is not real, that it is focused on the expectations of the audience about human behavior. For example, teenagers are already able to classify a family on the screen as false if life in that family looks trouble-free or, conversely, too unhappy.

Understanding the reality of what is happening in adolescents is also characterized by the ability to make aesthetic judgments about the actions that take place on the screen, based on the assessment of the quality of television products, which should not cause a sense of artificiality of events. 
When watching TV, teenagers rarely actualize their desire for knowledge and compassion. Adolescents are characterized by low concentration of attention on what is shown on TV. They, like adults, tend to passively perceive what is happening on the screen, even when they are alone or when they are disturbed.

Adolescents are more likely to be more critical of TV content than younger children, and are much less likely to identify themselves with television characters. Those who continue to believe in the reality of what is happening on the screen and identify with the cruel characters will be more aggressive, especially in the presence of fantasies on aggressive-heroic themes.

Although the inherited nature of violence is most often attributed to schoolchildren, due to the lack of their life experience and their belief in the reality of what is happening on the screen, most often violent acts copied from the TV screen are committed by adolescents. Programs often describe crime methods that teens can copy. Possessing the ability to think abstractly, teenagers are able to plan and reproduce in real life a fictional TV event, correcting the shortcomings of the crime that led to the failure in the film.

Adolescents' assessment of justice and injustice is often peculiar and relative, which, along with rebellious tendencies and a challenge to traditional conventions, makes them the only group of spectators who can admire criminals.

The following conditions can be identified that contribute to the imitation of crimes seen in movies and TV shows:

1) Strong identification with the TV show or its characters;

2) Constant strong involvement in the TV program at the fantasy level;

3) The ability to take real action.

Various studies in the field of suicidality show that adolescents are especially prone to use suicide techniques shown on television, especially if they have already been used by someone in real life.

About $80 \%$ of teens watch horror movies that frighten them. Observing violent scenes contributes to the fact that adolescents perceive the surrounding reality as pathetic and insignificant.

Interestingly, teenagers who very rarely watch TV consider themselves much less protected from criminals. However, teenagers who find violence on the screen unrealistic do not view the world around them as too cruel and scary, and do not exaggerate their sense of vulnerability to crime. In addition, adolescents who have been victims of crime tend not to rely on television as a source of reliable information.

Horror films are becoming relevant in the context of adolescent concerns about sexuality and role-playing identification. Studies that have found pleasure in watching horror movies have found that teenage girls respond positively to scenes where a woman has been a victim, less often than boys.

Discussion. Another study found that young people enjoy horror movies more when they are accompanied by a clearly frightened girl of the same age. However, girls enjoy horror movies more when they are in the company of a young man who is not scared. Thus, watching horror movies together gives boys the opportunity to 
demonstrate their superiority in frightening situations, and gives girls the opportunity to be calm.

Most teenagers prefer to watch music programs, although television is not ideal for broadcasting modern music. Numerous sociological studies confirm this opinion: according to various estimates, from 60 to $80 \%$ of older adolescents mark music programs as a priority. In addition, it should be noted that the widespread violence and violence against women in video clips make music videos less attractive to girls.

Studies show that teenagers aged 12-17 are one of the most popular audiences among those who consume erotic video products. Many teenagers watch similar scenes on television, in cinemas or videotapes at least once a month.

This interest of adolescents in erotica is quite understandable and significant, but it is impossible not to express some concern about the impact of pornography on male viewers. According to some researchers, the demonstration of pornographic products can lead to the following effects:

1. Justification of violence against women;

2. Increasing the impact of some myths about violence, one of which, for example, states that women really want to be raped. Unfortunately, there is no real data on whether such myths apply to girls. Although it can be assumed that watching violent porn movies increases the level of fear in girls and reduces their sense of personal dignity.

3. The growing tendency to use aggressive actions towards women.

For obvious ethical reasons, most pornography research is conducted on adult samples. However, it has been proven that adolescents are more exposed to the negative effects of pornography than adults, such as:

1) The youngest respondents among the group of adults were more influenced by pornography;

2) Lack of adolescent experience and strong interest in sexual intercourse leads to the fact that pornography becomes the first and often the only source of information about sexual behavior;

3) Sex education in schools focuses primarily on the biological side of the issue, so adolescents turn to television and video products to learn more about the social or interpersonal aspects of sexual relations.

Thus, before adolescence, children spend less time watching television than before. Their interests at this age include independence, sex and romantic relationships. Teenagers prefer music shows, thrillers, and (especially boys) movies of erotic and even pornographic content. Adolescents are more skeptical of the reality of television content and less likely to identify themselves with TV heroes. There are few who continue to believe in the reality of television content and identify with the characters, but they are more prone to aggressive actions.

The ability to abstract and understand at the highest level, as well as the tendency to disobey formal authorities, can contribute to adolescents' desire to imitate certain types of television aggression, crime, and suicide attempts.

Conclusions. The personal characteristics of the media also include its sociodemographic and cultural characteristics, region of residence. Psychophysiological 
properties also affect: speed and accuracy of information perception, memory volume, etc. These features largely determine the understanding and evaluation of a person's objective position, a set of ideas, goals and ways to achieve them, attitudes to social phenomena and problems, etc. These conditions and factors determine the information behavior of the individual: the real interaction with the channels of information, characterized by a certain state of interests, thematic and problematic advantages, the level of development of media materials, etc. These are the main provisions that characterize the information interaction of the subjects of the process of production and consumption of social information, the process of influencing the consciousness of the individual information technology, including manipulative.

\section{References:}

1. Rybakova L.N. The life line of a young person: value orientations and coping strategies // Personal values: collection of articles. scientific. tr. int. scientific-practical seminar "Personality in the modern world: to be or to seem?" International scientific conference. Dulatov readings (Kostanay, April 11-12, 2014) Retrieved from: https://www.isras.ru/index.php?page_id=1198\&id=3131\&printmode.

2. Yurchenko V.M. \& etc. (2011). Problems of sustainable development of regions: information security of a multi-ethnic society (based on materials from the South of Russia). 244 p., pp. 167-168.

3. Sorokin P.A. (1992). Person. Civilization. Society.

4. Sukhniv V.I. (2009). Internet Control: Trend and Practice. The strategy of the Russian. No. 2., P. 79-88.

5. The case of Varvara Karaulova. (2020). Retrieved from: https://ru.wikipedia.org/?oldid=106587796. 